\title{
Insertion polymorphisms of SINE200 retrotransposons within speciation islands of Anopheles gambiae molecular forms Federica Santolamazza ${ }^{\dagger 1}$, Emiliano Mancini ${ }^{\dagger 1}$, Frédéric Simard ${ }^{2}$, Yumin $\mathrm{Qi}^{3}$, Zhijian $\mathrm{Tu}^{3}$ and Alessandra della Torre*1
}

Address: ${ }^{1}$ Istituto Pasteur-Fondazione Cenci-Bolognetti, Sezione di Parassitologia, Dipartimento di Scienze di Sanità Pubblica, Università di Roma "La Sapienza", Italy, 2Institut de Recherche pour le Développement, UR016, and Institut de Recherche en Sciences de la Santé, Bobo-Dioulasso, Burkina Faso and ${ }^{3}$ Department of Biochemistry, Virginia Polytechnic Institute and State University, Blacksburg VA, USA

Email: Federica Santolamazza - federica.santolamazza@uniroma1.it; Emiliano Mancini - emiliano.mancini@uniroma1.it; Frédéric Simard - simard@ird.fr; Yumin Qi - yuqi@vt.edu; Zhijian Tu - jaketu@vt.edu; Alessandra della Torre* - ale.dellatorre@uniroma1.it

* Corresponding author †Equal contributors

Published: 25 August 2008

Malaria Journal 2008, 7:163

doi: $10.1186 / 1475-2875-7-163$
Received: II July 2008

Accepted: 25 August 2008

This article is available from: http://www.malariajournal.com/content/7/1/163

(c) 2008 Santolamazza et al; licensee BioMed Central Ltd.

This is an Open Access article distributed under the terms of the Creative Commons Attribution License (http://creativecommons.org/licenses/by/2.0), which permits unrestricted use, distribution, and reproduction in any medium, provided the original work is properly cited.

\begin{abstract}
Background: SINEs (Short INterspersed Elements) are homoplasy-free and co-dominant genetic markers which are considered to represent useful tools for population genetic studies, and could help clarifying the speciation processes ongoing within the major malaria vector in Africa, Anopheles gambiae s.s. Here, we report the results of the analysis of the insertion polymorphism of a nearly 200 bp-long SINE (SINE200) within genome areas of high differentiation (i.e. "speciation islands") of $M$ and $S A$. gambiae molecular forms.
\end{abstract}

Methods: A SINE-PCR approach was carried out on thirteen SINE200 insertions in M and S females collected along the whole range of distribution of $A$. gambiae s.s. in sub-Saharan Africa. Ten specimens each for Anopheles arabiensis, Anopheles melas, Anopheles quadriannulatus A and $15 \mathrm{M} / \mathrm{S}$ hybrids from laboratory crosses were also analysed.

Results: Eight loci were successfully amplified and were found to be specific for A. gambiae s.s.: 5 on $2 \mathrm{~L}$ chromosome and one on $\mathrm{X}$ chromosome resulted monomorphic, while two loci positioned respectively on $2 R$ (i.e. S200 2RI2D) and X (i.e. S200 X6.I) chromosomes were found to be polymorphic. S200 2RI2D was homozygote for the insertion in most S-form samples, while intermediate levels of polymorphism were shown in M-form, resulting in an overall high degree of genetic differentiation between molecular forms ( $\mathrm{Fst}=0.46 \mathrm{p}<0.00 \mathrm{I})$ and within M-form (Fst $=$ $0.46 \mathrm{p}<0.00 \mathrm{I}$ ). The insertion of $S 200 \times 6.1$ was found to be fixed in all $M$ - and absent in all Sspecimens. This led to develop a novel easy-to-use PCR approach to straightforwardly identify $A$. gambiae molecular forms. This novel approach allows to overcome the constraints associated with markers on the rDNA region commonly used for $M$ and $S$ identification. In fact, it is based on a single copy and irreversible SINE200 insertion and, thus, is not subjected to peculiar evolutionary patterns affecting rDNA markers, e.g. incomplete homogenization of the arrays through concerted evolution and/or mixtures of $\mathrm{M}$ and S IGS-sequences among the arrays of single chromatids.

Conclusion: The approach utilized allowed to develop new easy-to-use co-dominant markers for the analysis of genetic differentiation between $\mathrm{M}$ and $\mathrm{S}$-forms and opens new perspectives in the study of the speciation process ongoing within $A$. gambiae. 


\section{Background}

Anopheles gambiae sensu stricto (s.s.) is the most important vector of human malaria in Africa, causing $90 \%$ of the fatalcases worldwide [1]. It is believed that the differentiation of this very synanthropic and anthropophilic species within the A. gambiae complex is very recent, having taken place a few thousand years ago, as a result of expansion of human activities, which provided mosquitoes with new opportunities for breeding, eventually creating a worsening in malaria transmission in sub-Saharan Africa [2].

Chromosomal and molecular evidence from West Africa suggests that A. gambiae s.s. is currently undergoing incipient speciation leading to a segregation by reproductive isolation of (at least) two "molecular forms" provisionally named $M$ and S [3-6]. These forms have a largely overlapping range west of the Great Rift Valley, although their relative frequencies are very different on a micro-geographic scale, probably due to adaptation to differentiated larval habitats [7-10]. Due to common background of shared ancestral polymorphisms and to the still ongoing (although limited) gene flow, $\mathrm{M}$ and $\mathrm{S}$ forms are characterized by an overall very low degree of genetic differentiation, which has been shown to be mostly restricted to three unlinked regions of their genome. Two are adjacent to the centromere of $2 \mathrm{~L}$ and $\mathrm{X}$ chromosomes and the other is in a small portion of the $2 \mathrm{R}$ chromosome ("genomic islands of speciation" $[11,12])$. Although the overall picture suggests that we are observing speciation at its very early stages, the taxonomic status of $A$. gambiae s.s. molecular forms has not yet been established, nor has consensus been reached on whether or not they should be considered as entities on independent evolutionary trajectories, i.e. either as polymorphic components of a single species, or as emerging species. This issue is of great interest not only from an evolutionary point of view, but also because it has important implications both for malaria epidemiology and for the optimization of vector-based control strategies.

One major constraint to progress toward a solution of this debate is represented by difficulties in finding molecular markers with different/contrasting evolutionary dynamics, which would allow to get a better understanding of the strength of the reproductive barrier between molecular forms. In fact, so far, $\mathrm{M}$ and $\mathrm{S}$ forms are characterized by form-specific single nucleotide polymorphisms (SNPs) in the spacer regions of ribosomal DNA (rDNA) [13-15] and their population genetics has been analysed mostly by microsatellite approach, which present important intrinsic (e.g. low differentiation between $M$ and $S$ and homoplasy) and technical (e.g. need of sequencing facilities) drawbacks, which have limited their exploitation [16-19].
Recently, the analysis of the insertion patterns of transposable elements (TEs) (i.e. mobile genetic units capable of replicating and spreading in the host genome) has been successfully applied to support genetic differentiation between A. gambiae molecular forms [5,20-22]. Among TEs, Short INterspersed Elements (SINEs) have been extensively used as phylogenetic and population genetic markers in primate taxa [23] and, preliminary, in A. gambiae $[5,20]$. SINEs are $100-500$ bp long non-autonomous retrotransposons occurring in large copy numbers in eukaryotic genomes [24-27], that need to recruit enzymes encoded by Long INterspersed Elements (LINEs) to mobilize after transcription via RNA polymerase III $[28,29]$. They present unique features absent in most other TEs, which make them particularly useful for phylogenetic and population genetic studies: i) they can be considered 'homoplasy-free characters' because the chance of independent insertions/excisions into/from the same site is remote; therefore, the ancestral state is represented by the absence of the element at a locus and shared insertions at that locus are identical by descent $[23,30]$; ii) since they are short, they can be amplified even from low-quality genomic DNA and insertion polymorphisms at individual genomic locations can be easily and rapidly assayed by PCR [31]; iii) polymorphic SINEs are believed to be recently inserted and, thus, can help illuminate recent evolutionary events and resolve complexities in the population genetics structure [30-34].

SINE200 is a 200 bp element that is highly repetitive (>3,000 copies) and widespread in the A. gambiae s.s. genome [35]. Here we report the structure of this element and the results of a large scale analysis aimed to highlight different patterns of SINE200 insertion polymorphism between A. gambiae molecular forms at loci inside the speciation islands and propose the exploitation of these elements as novel molecular markers for the identification and/or population genetic analysis of $\mathrm{M}$ and $\mathrm{S}$ forms.

\section{Materials and methods \\ Anopheles gambiae samples}

The study was carried out on A. gambiae s.s. M- and S-form adults collected between 1998 and 2006 in 11 African Countries (Figure 1, Table 1). Ten specimens of other species of A. gambiae complex, i.e. A. arabiensis from Senegal and Zimbabwe [5,36], A. melas from Angola [10] and A. quadriannulatus A from Zimbabwe [36] were also analysed.

A cross between females of the GA-CAM (a M-form colony originated from field gravid females collected in Cameroon) and males of the GA-BF-5.7 colonies (a S-form colony originated from a single field gravid female collected in Burkina Faso) was performed and parental individuals and F1 hybrid females were analysed. 
Table I: Insertion polymorphisms at loci S200 X6.I and S200 2R I2D in Anopheles gambiae molecular forms.

\begin{tabular}{|c|c|c|c|c|c|c|c|c|}
\hline & \multirow[t]{2}{*}{ Country } & \multirow[t]{2}{*}{ Site } & \multirow[t]{2}{*}{ Form } & \multirow[t]{2}{*}{$\mathbf{N}$} & \multicolumn{2}{|c|}{$S 200 \times 6.1$} & \multicolumn{2}{|c|}{ S200 2RI2D } \\
\hline & & & & & $\mathbf{H}$ & $\mathbf{A F}$ & $\mathbf{H}$ & AF \\
\hline I & The Gambia & Maccarthy Island & $M$ & 15 & 0.00 & 1.00 & 0.40 & 0.53 \\
\hline 2 & Senegal & Kedougou & $S$ & 19 & 0.00 & 0.00 & 0.05 & 0.97 \\
\hline \multirow[t]{2}{*}{3} & Mali & Banambani & $\mathrm{S}$ & 32 & 0.00 & 0.00 & 0.00 & 0.98 \\
\hline & & & $M$ & 3 & 0.00 & 1.00 & 0.33 & 0.50 \\
\hline 4 & Ghana & Accra area & $\mathrm{S}$ & 28 & 0.00 & 0.00 & 0.00 & 1.00 \\
\hline \multirow[t]{2}{*}{5} & Burkina Faso & Bobo Dioulasso & $S$ & 27 & 0.00 & 0.00 & 0.00 & 1.00 \\
\hline & & & $M$ & 30 & 0.00 & 1.00 & 0.33 & 0.53 \\
\hline 6 & Ivory Coast & Buakè area & $\mathrm{S}$ & 20 & 0.00 & 0.00 & 0.00 & 1.00 \\
\hline 7 & Benin & Dassa area & $M$ & 33 & 0.00 & 1.00 & 0.24 & 0.41 \\
\hline \multirow[t]{2}{*}{8} & Nigeria & Kobape, Olugbo & $S$ & 20 & 0.00 & 0.00 & 0.00 & 1.00 \\
\hline & & & $M$ & 14 & 0.00 & 1.00 & 0.21 & 0.39 \\
\hline \multirow[t]{2}{*}{9} & Cameroon & Mangoum & $\mathrm{S}$ & 30 & 0.00 & 0.00 & 0.00 & 1.00 \\
\hline & & Kribi & $M$ & 30 & 0.00 & 1.00 & 0.00 & 1.00 \\
\hline \multirow[t]{2}{*}{10} & Angola & Cabinda & $S$ & 43 & 0.00 & 0.00 & 0.00 & 1.00 \\
\hline & & Luanda area & $M$ & 16 & 0.00 & 1.00 & 0.00 & 1.00 \\
\hline II & Tanzania & Nyakariro, Kwagole & $S$ & 26 & 0.00 & 0.00 & 0.00 & 1.00 \\
\hline
\end{tabular}

Sampling sites, number of specimens of $A$. gambiae molecular form analysed $(N)$, heterozygosity $(H)$ and allele frequency $(A F)$. Sampling sites are listed from west to east and numbered as in Figure I (for information on the samples and sampling sites see della Torre et al [5]).

Construction of SINE200 consensus sequence and copy number determination

SINE200 was first reported as part of the A. gambiae genome annotation [35]. Ninety-two SINE200 copies, which are $150 \mathrm{bp}$ or longer, were randomly selected from the PEST genome (version P3, http://www.vector base.org). Alignment was performed using ClustalX with gap open penalty $=10$, gap extension penalty $=0.05$ [37] The alignment was used as input for the program Consensus http://coot.embl.de/Alignment//consensus.html and a SINE200 consensus sequence was created using majority rule. At three positions, where there was no simple majority base, manual inspection allowed us to assign ambiguous bases (e.g., W for A or T). The A. gambiae genome database was then searched by BLAST using the above mentioned consensus as a query and the e-value cutoff was set at e-10. BLAST hits shorter than $150 \mathrm{bp}$ were not counted.

\section{Analysis of SINE200 insertion polymorphisms}

Genomic DNA was extracted with various standard procedures, and specimens were identified to species and molecular forms by PCR-RFLP [38,39]. SINE200 elements were located in silico by BLASTN searches on the genome sequence of the $A$. gambiae PEST genome using the obtained SINE200 consensus sequence as a query. Thirteen SINE200 insertions lying within the A. gambiae molecular form speciation islands (sensu Turner [11]) on $\mathrm{X}, 2 \mathrm{~L}$ and $2 \mathrm{R}$ chromosomes, and characterized by the presence of $500 \mathrm{bp}$ flanking regions showing a single hit in the genome, were selected. Primers were designed to amplify across the element using Primer 3 software [40]. The selected loci were named 'S200' followed by the abbreviation of the chromosomal arm $(2 \mathrm{~L}, 2 \mathrm{R}, \mathrm{X})$, by a number/ letter corresponding to the chromosomal location on the cytogenetic map [4] and by an additional number aimed to distinguish primer sets positioned on the same chromosome division. Genes annotated within a $20 \mathrm{~Kb}$ genome sequence including SINE200 insertions for each locus were retrieved from the PEST genome ver. Agam P3 Feb. 2006 (Table 2).

PCR reactions were carried out in a $25 \mu \mathrm{l}$ reaction which contained $1 \mathrm{pmol}$ of each primer, $0.2 \mathrm{mM}$ of each dNTP, $1.5 \mathrm{mM} \mathrm{MgCl} 2,2.5 \mathrm{U}$ Taq polymerase, and $0.5 \mu \mathrm{l}$ of template DNA extracted from a single mosquito. Thermocycler conditions were $94^{\circ} \mathrm{C}$ for $10 \mathrm{~min}$ followed by thirtyfive cycles of $94^{\circ} \mathrm{C}$ for $30 \mathrm{~s}, 54^{\circ} \mathrm{C}$ for $30 \mathrm{~s}$ and $72^{\circ} \mathrm{C}$ for 1 min., with a final elongation at $72^{\circ} \mathrm{C}$ for $10 \mathrm{~min}$, and a $4^{\circ} \mathrm{C}$ hold. The resulting products were analysed on $1.5 \%$ agarose gels stained with ethidium bromide, with low and high molecular weight bands corresponding to fragments containing or lacking the targeted SINE200, respectively.

PCR products representing 'filled' and 'empty' sites of S200 X6.1 locus on X chromosome were sequenced on both strands using ABI Big Dye Terminator v. 2 chemistry and an ABI Prism 3700 DNA Analyser. Multiple alignments were performed using ClustalX [37]. All sequences were deposited in GenBank under accession numbers $\underline{\text { EU881868-EU881887. }}$

Indices of polymorphism (i.e. SINE200 insertion frequency and heterozygosity) and differentiation (Fst) at 


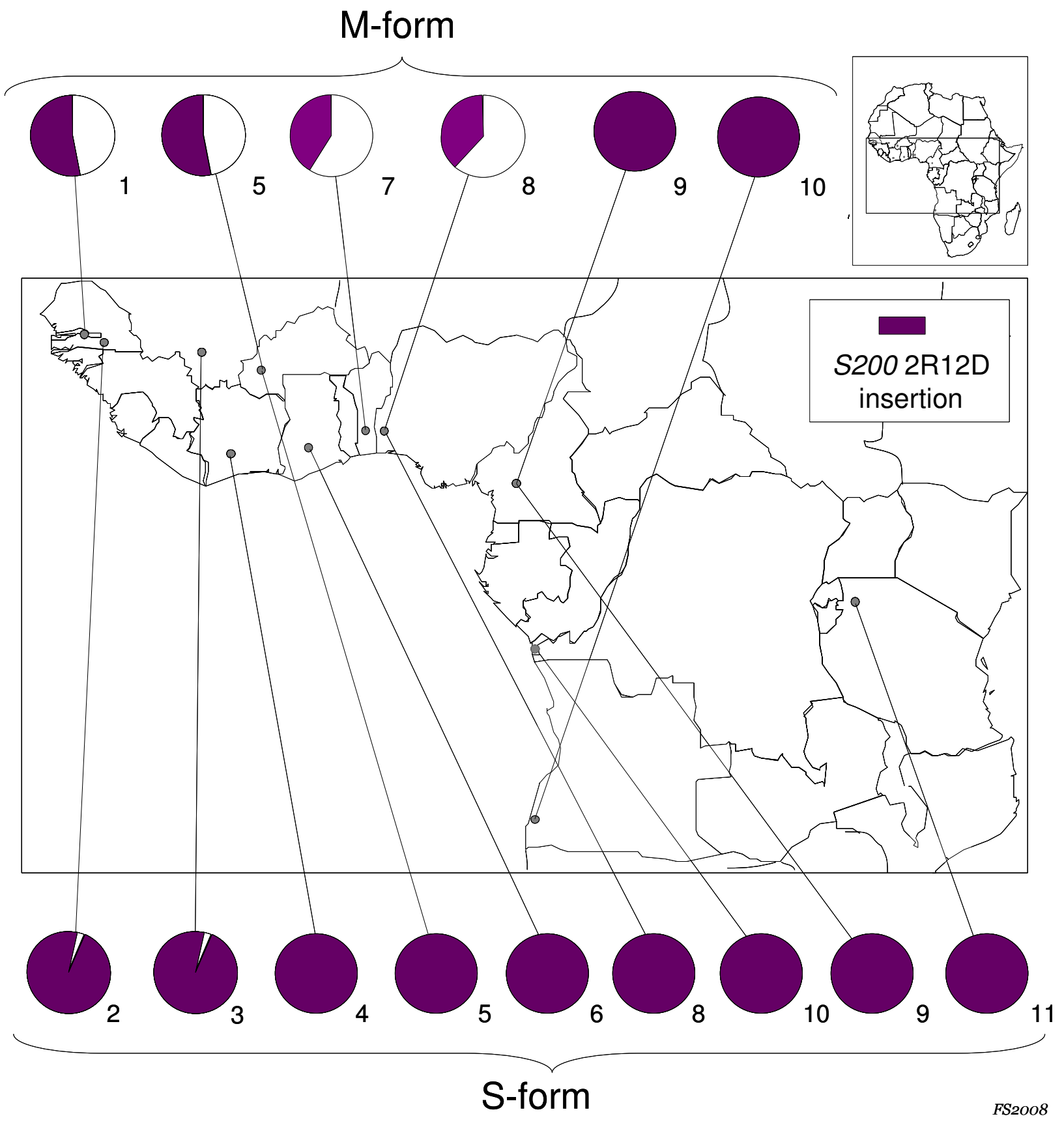

Figure I

Insertion frequencies at S200 2RI 2D locus in Anopheles gambiae M-form and S-form samples. Numbers below the pie-charts refer to the sampling sites as listed in Table I.

polymorphic loci were computed using Fstat 2.9.3.2 [41]. Significance was tested with Bonferroni-adjusted $P$-values, using the randomization approach implemented in Fstat.
Results

Structural features and chromosomal density of SINE200 in the A. gambiae genome

SINE200 is a previously discovered SINE family of the A. gambiae genome [35]. Here we further characterized SINE200 by constructing a consensus sequence on the basis of 92 SINE200 copies that are 150 bp or longer, 
Table 2: SINE200 primer list.

\begin{tabular}{|c|c|c|c|c|}
\hline Locus & SINE200 coordinate & Primer pair (forward/reverse) & Product size (bp) & Annotated genes (in $20 \mathrm{~Kb}$ ) \\
\hline \multirow[t]{2}{*}{$S 200 \times 6.1$} & Chromosome X: & 5'-TCGCCTTAGACCTTGCGTTA-3' & 479 & AGAP00I076 \\
\hline & $2295|445-2295| 67 \mid$ & 5'-CGCTTCAAGAATTCGAGATAC-3' & & (CYP4GI6 gene) \\
\hline \multirow[t]{2}{*}{$S 200 \times 6.2$} & Chromosome X: & 5'-TCGGGCCAATATAACACAC-3' & 588 & AGAP001094 \\
\hline & $24225524-24225731$ & 5'-AGGCGCCATGTACGTAACC-3' & & \\
\hline \multirow[t]{2}{*}{ S200 2L20A.I } & Chromosome 2L: & 5'-TGCCCTGTTCAAGATTTCAT-3' & 564 & none \\
\hline & $64|05|-641259$ & 5'-GGTCACTCACGCATACCGTCT-3' & & \\
\hline \multirow[t]{2}{*}{ S200 2L20A.2 } & Chromosome 2L: & 5'-ACGCCAGACGGTTTCATATC-3' & 611 & none \\
\hline & $977287-977497$ & 5'-ССТАTCTTTAATTTATATTCGC-3' & & \\
\hline \multirow[t]{2}{*}{ S200 2L20B.I } & Chromosome 2L: & 5'-AACCTTACAATACACAAGAAC-3' & 495 & AGAP004725 \\
\hline & $2796669-2796889$ & 5'-CAGGAAAACGACTACTCGAAC-3' & & AGAP004726 \\
\hline \multirow[t]{2}{*}{ S200 2L20B.2 } & Chromosome 2L: & 5'-CGCGTTGATTAATAATCCCAC-3' & 483 & none \\
\hline & $1191908-1192118$ & 5'-CCAGTCTCTGGACATGCTG-3' & & \\
\hline \multirow[t]{2}{*}{ S200 2L20B.3 } & Chromosome 2L: & 5'-TTATCTGCGCGTGAGTGG-3' & 515 & Intron of AGAP00469I \\
\hline & $|276754-127692|$ & 5'-ATACCGCCTAAACGCATG-3' & & (LIM gene) \\
\hline \multirow[t]{2}{*}{ S200 2RI2D } & Chromosome 2R: & 5'-AGAATGAATTGTATGGAACAGG-3' & 535 & AGAP002640 \\
\hline & $24868905-24869106$ & 5'-CTATTAAATGTGTCTCGCTCG-3' & & (GPR-OR38 gene) \\
\hline
\end{tabular}

SINE200 locus names, chromosomal locations and coordinates, PCR primers, 'filled' PCR product sizes and annotated genes within $20 \mathrm{~Kb}$ including the SINE200 loci investigated are indicated by Ensemble Gene ID, gene names are in brackets.

which is a small sample of all SINE200 copies (Figure 2). Analysis of the consensus sequence suggests that SINE200 has a typical structure, with a tRNA-related sequence at its 5 ' end, a conserved tRNA-unrelated sequence, and a simple repeat at its 3' end. Approximately $70 \mathrm{bp}$ of the 5' end of the SINE200 consensus is 94\% identical to the 5 ' end of a tRNA-Pseudo gene (AGAP000459). Sequences similar to the conserved A and B motifs for the polymerase III promoter were also found. Using the consensus sequence as a query, we showed that there are approximately 3,200 ubiquitous copies of SINE200 that are 150 bp or longer, and their density along the five chromosome arms ranges from 9.9 copies per Mbp (2R) to 12.9 copies per Mbp (X) (y3).

\section{Analysis of SINE200 insertion polymorphism}

The approach utilized was to design specific primers pair in the flanking regions of SINE200 insertions within M and $\mathrm{S} A$. gambiae speciation islands, where a higher degree of form-specific genetic differentiation was expected. Although SINE200 are present in several copies also in the target regions, the selection of the loci has been more complicated than expected, mainly due to abundance of repetitive sequences in heterochromatic regions in centromeric areas of A. gambiae genome [35]. Eventually, 13 primer pairs were initially designed. Among these, 5 did not successfully amplified the targeted SINE insertions, as they did not yield bands or provided aspecific PCR products, and the analysis was therefore focused on the remaining 8 loci. Table 2 reports chromosomal location and annotated genes retrieved in the neighbouring genome areas of the 8 successfully amplified SINE loci. Each of these loci was initially scored for SINE200 insertion polymorphism by PCR-amplifying $15 \mathrm{M}$-form and 15 S-form specimens from either Burkina Faso and Cameroon and 15 S-form from Mali. SINE200 element insertions were found fixed in both forms in all five loci on the 2L speciation island, polymorphic in two loci positioned on 2R (i.e. S200 2R12D) and X (i.e. S200 X6.1) chromosomes, respectively, whereas a second SINE200 on centromeric area of X chromosome ( 200 X6.2) was absent in all individuals analysed. SINE200 insertions were absent in all eight loci in the other analysed species of the A. gam-

Table 3: SINE200 copy number and density on different chromosomes in Anopheles gambiae s.s.

\begin{tabular}{lccc}
\hline Chromosome Arm & Length (Mbp) & SINE200 Copy No. & SINE200 Density (per Mbp) \\
\hline X & 24,393 & 314 & 12,9 \\
2L & 49,364 & 520 & 10,5 \\
2R & 61,545 & 610 & 9,9 \\
3L & 41,963 & 529 & 12,6 \\
3R & 53,201 & 626 & 11,8 \\
UNKNOWN & ND & 615 & ND
\end{tabular}

Copy number was determined by BLAST analysis using SINE200 consensus as query. The e-value cutoff is e-10. Only copies $>150$ bp are counted. $\mathrm{ND}=$ not determined. 


\section{Figure 2}

Consensus sequence of SINE200 in Anopheles gambiae s.s. SINE200 has a typical structure, with a tRNA-related sequence at its 5' end, a conserved tRNA-unrelated sequence, and simple repeats ('A' tail or tandem repeats) at its 3' end. The 5 ' end of the consensus (gray underlined) is $94 \%$ identical to the 5 ' end of a tRNA-Pseudo gene (AGAP000459). Sequences similar to the conserved $A$ and $B$ motifs for the polymerase III promoter are boxed. D:A/G/T; K:G/T; W: A/T.

biae complex (i.e. A. arabiensis, A. melas and A. quadriannulatus A).

The two polymorphic loci positioned on $\mathrm{X}$ and $2 \mathrm{R}$ chromosomes, were further studied by analysing additional $111 \mathrm{M}$-form and $200 \mathrm{~S}$-form specimens (Table 1 ). In the case of S200 2R12D locus, all S-form specimens resulted homozygotes for the insertion, except for few individuals from Mali (allele frequency $[\mathrm{AF}]=0.97$ ) and Senegal (AF $=0.98$ ), while intermediate levels of polymorphisms were shown in $\mathrm{M}$-form ( $\mathrm{AF}=0.38-0.53)$, resulting in an overall high degree of genetic differentiation between molecular forms $($ Fst $=0.46 \mathrm{P}<0.001)$. Moreover, preliminary results show intra-form differentiation between west (i.e. Burkina Faso, Nigeria and Benin) and west-central (i.e. Cameroon and Angola) M-subsamples (Fst $=0.46 \mathrm{P}<$ 0.001 ), while no significant variation was found within each subsample. On the other hand, no intra-form differentiation at the same locus was recorded in the S-form sample within the same range of distribution.

Remarkable differences among molecular forms were found at locus $S 200$ X6.1 (Table 1): in all samples the insertion was fixed in $\mathrm{M}$-form individuals, from which a single PCR product of 479 bp was amplified, and absent in S-form specimens, from which a 249 bp product was obtained (Figure 3). As expected, laboratory-reared specimens of both molecular forms analysed $(\mathrm{N}=60)$ showed the same pattern of insertion at $S 200$ X6.1 locus. Moreover, the analysis of $\mathrm{M} / \mathrm{S}$ hybrids resulting from laboratory crosses produced consistent results, yielding both PCRbands from all hybrid $M / S$ specimens analysed $(\mathrm{N}=15)$ (Figure 3). The absence of SINE200 at this locus was confirmed in all the other A. gambiae s.l. member species ana- lysed. Interestingly, the PCR product obtained from $A$. arabiensis was represented by a 223 bp band, due to a 26 bp deletion in the $S 200 \times 6.1$ flanking region. In addition, the alignment of $S 200$ X6.1 flanking regions sequences showed (Figure 4): i) fixed mutations at 3 positions in the alignment (positions 16, 74, 359) differentiating both $A$. gambiae s.s. molecular forms from A. arabiensis, A. melas and $A$. quadriannulatus; ii) mutations in two positions (pos. 17, 69) differentiating the M-form from all the other taxa analysed; iii) a very high conservation in the

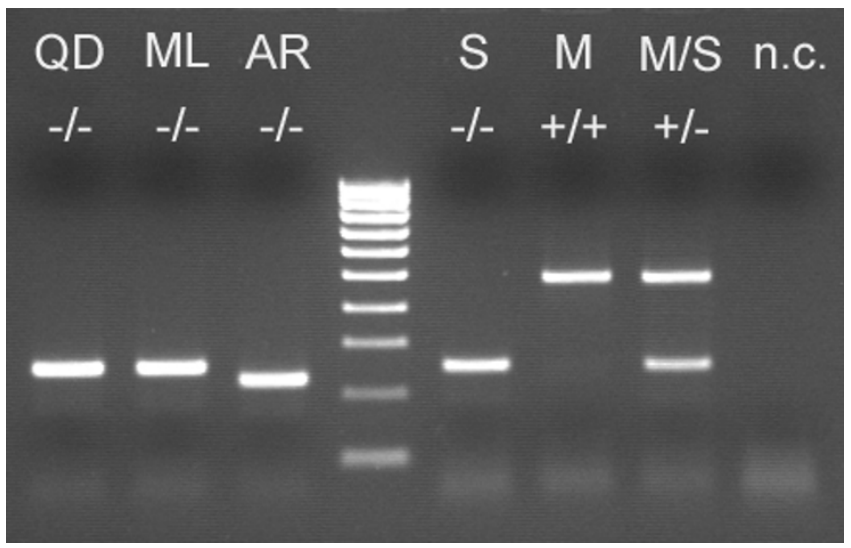

Figure 3

Diagnostic PCR based on S200 X6.I in Anopheles gambiae s.I. PCR results from locus S200 X6.I indicating the presence $(+)$ or absence $(-)$ of the insertion in females of Anopheles gambiae species complex. $\mathrm{QD}=A$. quadriannulatus $A ; M L=A$. melas; $A R=A$. arabiensis; $S=A$. gambiae $S$-form; $M$ = A. gambiae $M$-form; $M / S=M / S$ hybrids from laboratory crosses; n.c. $=$ negative control. Ladder $=100$ bp $($ BIOLINE HyperLadder IV). 

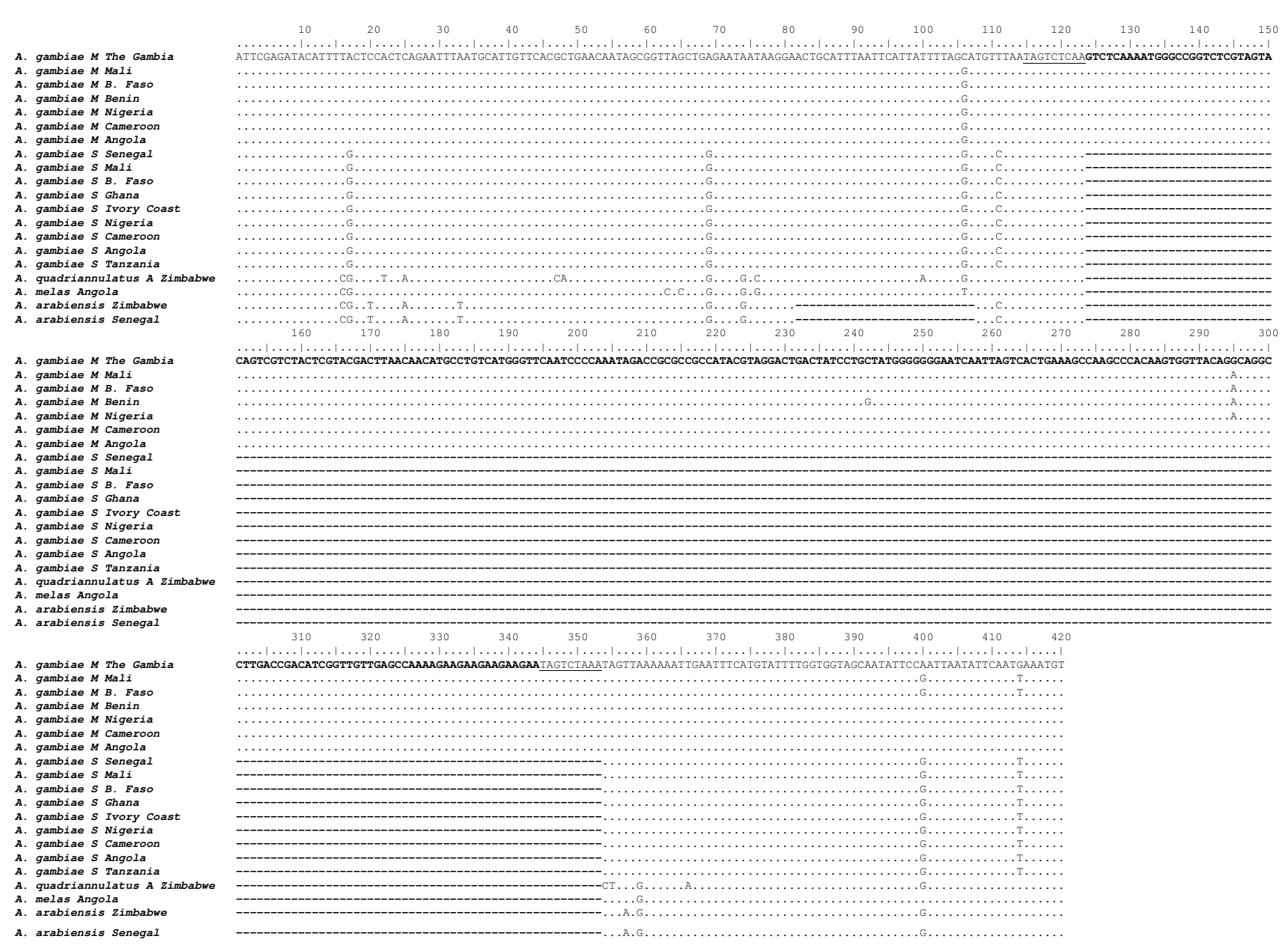

\section{Figure 4}

Sequence alignment of $S 200 \times 6 . I$ and flanking regions in the Anopheles gambiae s.I. Nucleotide substitutions at each position are indicated with the appropriate nucleotide. Deletions are denoted by dashes (-). The nucleotide deletion of 26 bp in the flanking region of $S 200 \times 6$.I for A. arabiensis corresponds to positions 82-107. Deletion at positions I24-353 corresponds to the absence of the S200 X6.I element in A. gambiae S form, A. quadriannulatus A, A. arabiensis and A. melas. Target site duplications (TSDs) are underlined.

sequence of the element was found in all $\mathrm{M}$ individuals analysed.

\section{Discussion}

The analysis of the consensus sequence of SINE200 indicates that it is a typical tRNA-related SINE element. In fact, it has a tRNA-related region at the $5^{\prime}$ end with the A and $\mathrm{B}$ boxes found in polymerase III promoters. It also has a variable number of the AAG tandem repeat at the 3 ' end, which is also typical for tRNA-related SINEs [42]. The middle of SINE200 is a conserved sequence that is not related to tRNA sequences, as already described for other eukaryotic SINE elements [43].
Eight SINE200 loci within A. gambiae s.s. speciation islands were analysed, as follows: i) two on the X-chromosome, one of which (i.e. $\$ 200$ X6.2) was absent in all specimens tested, while the other (i.e. S200 X6.1) was fixed in the $\mathrm{M}$-form and absent in the S-form samples; ii) one on 2R (i.e. S200 2R12D), which was found polymorphic in both molecular forms; and iii) five on $2 \mathrm{~L}$, which were all fixed in both forms. The observed high frequency of fixation of the insertions in centromeric areas probably reflects a common behaviour of transposable elements, which tend to accumulate in regions of reduced recombination [44], as also suggested for other retrotrasposon classes in the A. gambiae genome [21]. 
The observed differences in the allelic frequencies at $S 200$ 2R12D locus highlight a significant reduction of geneflow between the two molecular forms. This represents an additional evidence in support of the relevance of this small chromosomal region in the speciation process ongoing within A. gambiae s.s., as proposed by Turner $e$ t al [11]. Interestingly, S200 2R12D lies in close proximity (about $20 \mathrm{~Kb}$ ) to an odour receptor gene (i.e. GPR-OR38), which has been suggested to be likely related to reproductive isolation between molecular forms [12]. Moreover, a similar level of differentiation was observed within $\mathrm{M}$ form, suggesting a subdivision between western and western-central M-populations (Figure 1). This sub-structuring observed within the $\mathrm{M}$-form is consistent with recent evidence from a wide microsatellite analysis carried out on the same M-form populations [45] and with previous observations by Slotman et al [6], who suggests that $\mathrm{M}$ populations from Mali and Cameroon may no longer be considered a "single entity". It should be noted, however, that $S 200$ 2R12D locus lies within 2Rb chromosomal inversion, which is shared by $\mathrm{M}$ and $\mathrm{S}$ forms and shows different frequencies in various eco-geographic areas $[4,5]$. It is thus possible that the spread of this element in natural populations is affected by $2 \mathrm{Rb}$ inversion polymorphism, although preliminary data show that $S 200$ 2R12D insertion is not exclusive of one of the two alternative chromosomal arrangements (i.e. $2 \mathrm{R}+\mathrm{b}$ and $2 \mathrm{Rb}$ ). Further studies on larger karyotyped samples are ongoing to evaluate a possible association between the $2 \mathrm{Rb}$ inversion and the element insertion.

As it is recognized that SINEs do not excide from a genome after their insertion $[23,30]$ and since all SINE200 loci analysed were found to be specific of A. gambiae s.s., the analysed insertions likely occurred after divergence of this species from the other members of the A. gambiae complex. Moreover, S200 X6.1 was found to be exclusive of and highly conserved in the M-form and, therefore, probably recently integrated in its genome after divergence of molecular forms within the chromosome-X speciation island. This locus lies in proximity of CYP4G16, a gene of the cytochrome P450 family which has been indicated as a candidate gene in the incipient speciation process ongoing within A. gambiae s.s. [11].

In addition to the above cited indications in favour of a possible fruitful exploitation of SINE200 in the study of the sub-structuring of A. gambiae, the exclusive presence of S200 X6.1 in the M-form allows to propose a novel straightforward approach to distinguish A. gambiae s.s. molecular forms. In fact, all methods developed so far for their identification are based on point mutations in IGS region of rDNA, which is formed by several tandem arrays known to be subjected to concerted evolution. Thus, possible diagnostic problems, in particular in the interpreta- tion of hybrid $\mathrm{M} / \mathrm{S}$ patterns, may arise from incomplete homogenization of the arrays through concerted evolution and/or mixtures of $\mathrm{M}$ and S IGS-sequences among the arrays of single chromatids, due to recombination between copies on the X and Y chromosomes [15]. The S200 X6.1 locus, on the other hand, although located only about $1 \mathrm{Mb}$ from IGS-region, does not show these constraints, being present in a single copy on the X-chromosome. Moreover, it is important to highlight that PCRRFLP $[38,39]$, and IMP-PCR $[13,46]$ methods currently used for $\mathrm{M}$ and $\mathrm{S}$ identification are based on the recognition of single/few mutation(s), and thus subjected to homoplasy. On the other hand, the PCR diagnostic approach here proposed is based on the specific and irreversible insertion of a $230 \mathrm{bp}$ element in the $\mathrm{M}$-form (and its absence in S-form), thus allowing an unambiguous, simple and straightforward recognition of $\mathrm{M}$ and $\mathrm{S}$ forms (Figure 3). It is also interesting to note that, although the $S$-form amplicon is identical to those of $A$. melas and $A$. quadriannulatus, the 26 bp deletion reported for A. arabiensis allows to propose the use of the novel approach to discriminate A. gambiae from A. arabiensis specimens without preliminary species identification in large areas of sub-saharan Africa where A. gambiae molecular forms and A. arabiensis are the only species of the complex present.

\section{Conclusion}

The approach utilized opens new perspectives in the studies of A. gambiae molecular forms. Further analyses on SINE200 loci mapping in different areas of A. gambiae genome are ongoing based on preliminary selection by a genome-wide TE-display approach of form-specific or polymorphic loci, to eventually provide additional, new efficient co-dominant markers for the analysis of genetic differentiation between $\mathrm{M}$ and S-forms.

\section{Competing interests}

The authors declare that they have no competing interests.

\section{Authors' contributions}

FS and EM carried out the molecular processing, participated in the analysis and interpretation of data, and in the drafting of the manuscript; YQ contributed to the molecular processing; FS collected part of the samples and to the drafting of the manuscript; ZT proposed the study and contributed to the set-up of the experimental approach, data analysis and drafting of the manuscript; AdT conceived and coordinated the study and wrote the manuscript. All authors read and approved the final manuscript.

\section{Acknowledgements}

We are grateful to all scientists and entomology teams who provided samples utilized in this study; we especially thank K. Adasi, M. Akogbeto, T. Baldet, G. Carrara, C. Costantini, P.J. Cani, C. Curtis, I. Dia, J. Dossou-yovo, N. Elissa, F. Fortes, A. Mendjibe, YT. Touré, W. Takken, S. Torr and G. Vale 
for help with sample collections. We also thank JMC. Ribeiro for help with bioinformatic analyses of SINE200 and V. Petrarca and J. Pinto for useful discussion on data and manuscript. The project was funded by $\mathrm{NIH}$-grant Al42I2I to ZT. EM was supported by Compagnia di San Paolo (Torino, Italy) in the context of the Italian Malaria Network.

\section{References}

I. Breman JG, Alilio MS, Mills A: Conquering the intolerable burden of malaria: what's new, what's needed: a summary. Am J Trop Med Hyg 2004, 7 I: I-I5.

2. Coluzzi M: The clay feet of the malaria giant and its African roots: hypotheses and inferences about origin, spread and control of Plasmodium falciparum. Parassitologia 1999, 4I:277-283.

3. della Torre A, Fanello C, Akogbeto M, Dossou-yovo J, Favia G, Petrarca V, Coluzzi M: Molecular evidence of incipient speciation within Anopheles gambiae s.s. in West Africa. Insect Mol Biol 2001, 10:9-18.

4. Coluzzi M, Sabatini A, della Torre A, Di Deco MA, Petrarca V: A polytene chromosome analysis of the Anopheles gambiae species complex. Science 2002, 298: |4I5-1418.

5. della Torre A, Tu Z, Petrarca V: On the distribution and genetic differentiation of Anopheles gambiae s.s. molecular forms. Insect Biochem Mol Biol 2005, 35:755-769.

6. Slotman MA, Tripét F, Cornel AJ, Meneses CR, Lee Y, Reimer LJ, Thiemann TC, Fondjo E, Fofana A, Traoré SF, Lanzaro GC: Evidence for subdivision within the $M$ molecular form of Anopheles gambiae. Mol Ecol 2007, I 6:639-649.

7. della Torre A, Costantini C, Besansky NJ, Caccone A, Petrarca V, Powell JR, Coluzzi M: Speciation within Anopheles gambiae - the glass is half full. Science 2002, 298: I I5- II7.

8. Wondji C, Frederic S, Petrarca V, Etang J, Santolamazza F, della Torre A, Fontenille D: Species and populations of the Anopheles gambiae complex in Cameroon with special emphasis on chromosomal and molecular forms of Anopheles gambiae s.s. J Med Entomol 2005, 42:998-1005.

9. Lehmann T, Dalton R, Kim EH, Dahl E, Diabaté A, Dabiré R, Dujardin JP: Genetic contribution to variation in larval development time, adult size, and longevity of starved adults of Anopheles gambiae. Infect Genet Evol 2006, 6:410-416.

10. Calzetta M, Santolamazza F, Carrara GC, Cani PJ, Fortes F, Di Deco MA, della Torre A, Petrarca V: Distribution and chromosomal characterization of the Anopheles gambiae complex in Angola. Am J Trop Med Hyg 2008, 78:169-175.

II. Turner TL, Hahn MW, Nuzhdin SV: Genomic islands of speciation in Anopheles gambiae. PLoS Biol 2005, 3:e285.

12. Turner TL, Hahn MW: Locus- and population-specific selection and differentiation between incipient species of Anopheles gambiae. Mol Biol Evol 2007, 24:2132-2138.

13. Favia G, Lanfrancotti A, Spanos L, Siden-Kiamos I, Louis C: Molecular characterization of ribosomal DNA polymorphisms discriminating among chromosomal forms of Anopheles gambiae s.s. Insect Mol Biol 200I, 10:19-23.

14. Gentile G, Slotman M, Ketmaier V, Powell JR, Caccone A: Attempts to molecularly distinguish cryptic taxa in Anopheles gambiae s.s. Insect Mol Biol 200I, I 0:25-32.

I5. Wilkins EE, Howell PI, Benedict MQ: $\mathbf{X}$ and $\mathbf{Y}$ chromosome inheritance and mixtures of rDNA intergenic spacer regions in Anopheles gambiae. Insect Mol Biol 2007, 16:735-74I.

16. Lanzaro GC, Touré YT, Carnahan J, Zheng L, Dolo G, Traoré S, Petrarca $V$, Vernick KD, Taylor CE: Complexities in the genetic structure of Anopheles gambiae populations in west Africa as revealed by microsatellite DNA analysis. Proc Natl Acad Sci USA 1998, 95: |4260-|4265.

17. Lehmann T, Licht M, Elissa N, Maega BT, Chimumbwa JM, Watsenga FT, Wondji CS, Simard F, Hawley WA: Population Structure of Anopheles gambiae in Africa. J Hered 2003, 94:133-I47.

18. Wang R, Zheng L, Touré YT, Dandekar T, Kafatos FC: When genetic distance matters: measuring genetic differentiation at microsatellite loci in whole-genome scans of recent and incipient mosquito species. Proc Natl Acad Sci USA 200I, 98:10769-10774.

19. Wang-Sattler R, Blandin S, Ning Y, Blass C, Dolo G, Touré YT, delle Torre A, Lanzaro GC, Steinmetz LM, Kafatos FC, Zheng L: Mosaic genome architecture of the Anopheles gambiae species complex. PLOS ONE 2007, 2:el 249.

20. Barnes MJ, Lobo NF, Coulibaly MB, Sagnon NF, Costantini C, Besansky NJ: SINE insertion polymorphism on the $\mathbf{X}$ chromosome differentiates Anopheles gambiae molecular forms. Insect $\mathrm{Mol}$ Biol 2005, | 4:353-363.

21. Boulesteix M, Simard F, Antonio-Nkondjio C, Awono-Ambene HP, Fontenille D, Biémont C: Insertion polymorphism of transposable elements and population structure of Anopheles gambiae $\mathbf{M}$ and $\mathbf{S}$ molecular forms in Cameroon. Mol Ecol 2007, 16:441-452.

22. Esnault C, Boulesteix M, Duchemin JB, Koffi AA, Chandre F, Dabiré R, Robert V, Simard F, Tripét F, Donnelly MJ, Fontenille D, Biémont $C$ : High genetic differentiation between the $M$ and $S$ molecular forms of Anopheles gambiae in Africa. PLOS ONE 2008, 3:el968.

23. Batzer MA, Deininger PL: Alu repeats and human genomic diversity. Nat Rev Genet 2002, 3:370-379.

24. Okada N: SINEs: short interspersed repeated elements of the eukaryotic genome. Trends Ecol Evol 1991, 6:358-36I.

25. Ohshima K, Hamada M, Terai $Y$, Okada N: The 3' ends of tRNAderived short interspersed repetitive elements are derived from the 3 ' ends of long interspersed repetitive elements. Mol Cell Biol 1996, I6:3756-3764.

26. Deininger PL, Batzer MA: Mammalian retroelements. Genome Res 2002, I 2: 1455-1465.

27. Ohshima K, Okada N: SINEs and LINEs: symbionts of eukaryotic genomes with a common tail. Cytogenet Genome Res 2005, I 1 0:475-490.

28. Kajikawa M, Okada N: LINEs mobilize SINEs in the eel through a shared 3' sequence. Cell 2002, I I I:433-444.

29. Dewannieux M, Esnault C, Heidmann T: LINE-mediated retrotransposition of marked Alu sequences. Nat Genet 2003, 35:4I-48.

30. Shedlock AM, Okada N: SINE insertions: powerful tools for molecular systematics. Bioessays 2000, 22: |48-160.

31. Ray DA: SINEs of progress: Mobile element applications to molecular ecology. Mol Ecol 2007, I 6: 19-33.

32. Hillis DM: SINEs of the perfect character. Proc Natl Acad Sci USA 1999, 96:9979-998I.

33. Shedlock AM, Milinkovitch MC, Okada N: SINE evolution, missing data, and the origin of whales. Syst Biol 2000, 49:808-8I7.

34. Shedlock AM, Takahashi K, Okada N: SINEs of speciation: tracking lineages with retroposons. Trends Ecol Evol 2004, 1 9:545-553.

35. Holt RA, Subramanian GM, Halpern A, Sutton GG, Charlab R, Nusskern DR, Wincker P, Clark AG, Ribeiro JM, Wides R, Salzberg SL, Loftus B, Yandell M, Majoros WH, Rusch DB, Lai Z, Kraft CL, Abril JF, Anthouard V, Arensburger P, Atkinson PW, Baden $\mathrm{H}$, de Berardinis V, Baldwin D, Benes V, Biedler J, Blass C, Bolanos R, Boscus D, Barnstead M, Cai S, Center A, Chaturverdi K, Christophides GK, Chrystal MA, Clamp M, Cravchik A, Curwen V, Dana A, Delcher A, Dew I, Evans CA, Flanigan M, Grundschober-Freimoser A, Friedli L, Gu Z, Guan P, Guigo R, Hillenmeyer ME, Hladun SL, Hogan JR, Hong YS, Hoover J, Jaillon O, Ke Z, Kodira C, Kokoza E, Koutsos A, Letunic I, Levitsky A, Liang Y, Lin JJ, Lobo NF, Lopez JR, Malek JA, Mclntosh TC, Meister S, Miller J, Mobarry C, Mongin E, Murphy SD, O'Brochta DA, Pfannkoch C, Qi R, Regier MA, Remington K, Shao H, Sharakhova MV, Sitter CD, Shetty J, Smith TJ, Strong R, Sun J, Thomasova D, Ton LQ, Topalis $P$, Tu Z, Unger MF, Walenz B, Wang A, Wang J, Wang $M$, Wang X, Woodford KJ, Wortman JR, Wu M, Yao A, Zdobnov EM, Zhang H, Zhao Q, Zhao S, Zhu SC, Zhimulev I, Coluzzi M, della Torre A, Roth CW, Louis C, Kalush F, Mural RJ, Myers EW, Adams MD, Smith HO, Broder S, Gardner MJ, Fraser CM, Birney E, Bork P, Brey PT, Venter JC, Weissenbach J, Kafatos FC, Collins FH, Hoffman SL: The genome sequence of the malaria mosquito Anopheles gambiae. Science 2002, 298: 129-149.

36. Torr SJ, della Torre A, Calzetta M, Costantini C, Vale GA: Towards a fuller understanding of mosquito behaviour: use of electrocuting grids to compare the odour-orientated responses of Anopheles arabiensis and An. quadriannulatus in the field. Med Vet Entomol 2008, 22:93-108.

37. Thompson JD, Gibson TJ, Plewniak F, Jeanmougin F, Higgins DG: The ClustalX windows interface: flexible strategies for multiple sequence alignment aided by quality analysis tools. Nucleic Acids Research 1997, 24:4876-4882. 
38. Fanello C, Santolamazza F, della Torre A: Simultaneous identification of species and molecular forms of the Anopheles gambiae complex by PCR-RFLP. Med Vet Entomol 2002, 16:46I-464.

39. Santolamazza F, della Torre A, Caccone A: Short report: A new polymerase chain reaction-restriction fragment length polymorphism method to identify Anopheles arabiensis from An. gambiae and its two molecular forms from degraded DNA templates or museum samples. Am J Trop Med Hyg 2004, 70:604-606.

40. Rozen S, Skaletsky H: Primer3 on the WWW for general users and for biologist programmers. Methods Mol Biol 2000, 132:365-386.

41. Goudet J: FSTAT: A program to estimate and test gene diversities and fixation indices, Version 2.9.3. 200I [http:// www2.unil.ch/popgen/softwares/fstat.htm].

42. Tu Z: Genomic and evolutionary analysis of Feilai, a diverse family of highly reiterated SINEs in the yellow fever mosquito, Aedes aegypti. Mol Biol Evol 1999, 16:760-772.

43. Feschotte C, Fourrier N, Desmons I, Mouches C: Birth of a retroposon: the Twin SINE family from the vector mosquito Culex pipiens may have originated from a dimeric tRNA precursor. Mol Biol Evol 200I, 18:74-84.

44. Bartolomé $\mathrm{C}$, Maside $\mathrm{X}$ : The lack of recombination drives the fixation of transposable elements on the fourth chromosome of Drosophila melanogaster. Genet Res 2004, 83:91-100.

45. Santolamazza F, Pinto J, Mancini E, Caputo B, Pombi M, Simard F, Caccone A, Tu Z, Petrarca V, della Torre A: Analysis of genetic diversity within Anopheles gambiae s.s. M-form [Abstract]. Parassitologia 2008, 50:102.

46. Wilkins EE, Howell PI, Benedict MQ: IMP PCR primers detect single nucleotide polymorphisms for Anopheles gambiae species identification, Mopti and Savanna rDNA types, and resistance to dieldrin in Anopheles arabiensis. Malar J 2006, 5:125.

Publish with Bio Med Central and every scientist can read your work free of charge

"BioMed Central will be the most significant development for disseminating the results of biomedical research in our lifetime. "

Sir Paul Nurse, Cancer Research UK

Your research papers will be:

- available free of charge to the entire biomedical community

- peer reviewed and published immediately upon acceptance

- cited in PubMed and archived on PubMed Central

- yours - you keep the copyright
BioMedcentral 